\title{
The effect of erythropoietin to pulmonary injury and mast cells secondary to acute pancreatitis
}

\author{
Tanzer Korkmaz ${ }^{1 *}$, Nurettin Kahramansoy ${ }^{2}$, Ali Kilicgun ${ }^{3}$ and Tulin Firat ${ }^{4}$
}

\begin{abstract}
Background: Acute pancreatitis is a life-threatening necroinflammatory disease that is characterized by systemic inflammatory response syndrome and acute lung injury even in its very first days. Erythropoietin (EPO) is a hormone considered as an antiapoptotic and cytoprotective with observed receptors of anti-inflammatory effect on organs apart from the liver and the kidneys. In this study, the effects of EPO on pulmonary mast cells and on secondary injury caused by acute pancreatitis are investigated.
\end{abstract}

Methods: Twenty one Wistar Albino rats were divided into three groups—sham, control, and EPO groups—with 7 rats per group. Pancreatitis was induced by administering $4.5 \%$ sodium taurocholate into the pancreatic duct. A $1000 \mathrm{U} / \mathrm{kg} /$ day dosage (three times) of EPO was administered to the EPO group. Blood urea nitrogen (BUN), creatinine, amylase, and troponin I in the serum were studied; and lung, kidney, brain, and heart tissues were examined histopathologically.

Results: There were no histopathological changes in the other organ tissues except for the lung tissue. Compared to the control group, the EPO group showed significantly reduced alveolar hemorrhage, septal neutrophil infiltration, lung wall thickness score, and mast cell count in the lung tissue.

Conclusions: Administration of EPO reduces the mast cell count and lung wall thickness, and it reduces the alveolar hemorrhage and septal infiltration induced by acute pancreatitis.

Keywords: Erythropoietin, Acute lung injury, Mast cell, Acute pancreatitis

\section{Background}

Acute pancreatitis (AP) is a life-threatening necroinflammatory disease. Systemic inflammatory response syndrome (SIRS) that develops during the course of the disease and owing to multiple organ failure (MOF) is a major cause of morbidity and mortality. A large number of patients lose their lives due to acute lung injury (ALI) and acute respiratory distress syndrome (ARDS) [1]. The disease confines itself to a single organ $80 \%$ of the time; however, with the development of MOF, it is related to mortality by $40 \%[2,3]$. Although supporting therapies have been developed for the treatment of pancreatitis, definite treatments capable of reducing the severeness of the inflammation do not yet exist [4].

The erythropoietin (EPO) gene is located on chromosome 7 and encodes a polypeptide chain containing 193

\footnotetext{
* Correspondence: tanzerkorkmaz@gmail.com

'Department of Emergency, Medicine of Faculty, Abant Izzet Baysal University, Bolu, Golkoy, Turkey

Full list of author information is available at the end of the article
}

amino acids. The circulatory mature protein is a 30.4$\mathrm{kDa}$ glycoprotein that has a span of 165 amino acids [5]. $\mathrm{EPO}$ is a hormone mainly produced in the kidneys that is effective in maintaining the erythrocyte mass in circulation. Furthermore, recent studies have shown that in addition to the liver and the kidneys, EPO and its receptors are also present in organs such as the heart and the brain [5]. By its receptors, EPO, as a cytokine has antiapoptotic and cytoprotective effects [5-7].

Although mast cells are present in all body tissues, they are mostly observed around the capillaries of the skin and the respiratory system and the vessels of the lymphatic system $[8,9]$. It has been reported that mast cells play a role in inflammatory and allergic diseases of the respiratory system [10-12]. In ischemic injuries, ALI fundamentally develops through the release of mast-cell-activated cytokines such as histamine and tryptase [12,13]. It is also reported that mast cells increase inflammation within seconds in lung tissue through these cytokines $[9,13]$.

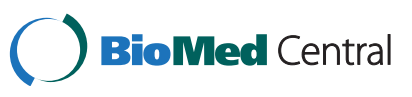


In this study, it is aimed to investigate histopathological effects of EPO administration on the tissue in distant organ damage induced by AP and variations in the mast cell count.

\section{Methods}

This study was approved by the ethics committee of Abant Izzet Baysal University (No. 375/2012). Twenty-one healthy male Wistar Albino rats (weight: 150-200 g) were housed in a climate-controlled facility and given ad libitum access to food and water.

\section{Experimental groups}

21 rats were randomly separated into three groups-sham, control, and EPO (with induced AP and application of EPO) groups-with 7 rats per group. After the inducement of pancreatitis, a dosage of $1000 \mathrm{U} / \mathrm{kg} /$ day (5 IU) of intraperitoneal EPO (Eprex, $2000 \mathrm{U} / 0.5 \mathrm{~mL}$ from Gürel İlaç Ticaret, İstanbul) was administered for three days to the EPO Group.

\section{Study Protocol}

All interventions for rats were performed by the same team. In a temperature-controlled room, anesthesia was induced by intramuscular injection of a combination of xylazine hydrochloride (10 mg/kg, Rompun, Bayer, Toronto, Canada) and ketamine hydrochloride $(50 \mathrm{mg} / \mathrm{kg})$, Ketalar, Parke Davis-Eczacibaşı, İstanbul, Turkey). The rats were fixed in a supine position and secured in the dissection tray. Their skin was shaved with povidone-iodine solution and prepared for aseptic surgery. The intestinal region was accessed by means of midline laparotomy, and the duodenum was pulled downward and laterally. The pancreatic duct was exposed and entered transduodenally using a $26 \mathrm{G}$ catheter. The sham group was administered 0.2 cc serum physiologic through the pancreatic duct, and the control as well as the EPO groups were administered a solution of $0.2 \mathrm{cc}$ serum physiologic dissolved in $4.5 \%$ sodium taurocholate (NaTC) ((Sigma-Aldrich, St. Louis, MO, USA) through slow infusion into the pancreatic duct [14]. The transduodenal bile duct and anterior abdominal walls were closed with $6 / 0$ prolen and $3 / 0$ silk suture, respectively. After the procedure, the EPO group was administered $1000 \mathrm{U} / \mathrm{kg}$ EPO intraperitoneally at intervals of 1,24 , and $48 \mathrm{~h}$, and the sham and control groups were administered the same volume of serum physiologic intraperitoneally. At the end of the third day, after sedation, all subjects were sacrificed by exsanguination, and the heart, kidney, brain, and pulmonary segments were removed. The blood, blood urea nitrogen (BUN), creatinine, amylase, and troponin I were examined.

\section{Biological examination}

After the procedure, biochemical analyses were performed on blood samples taken from the abdominal aorta. BUN, creatinine, and amylase tests were performed using COBAS Integra 800 autoanalyzer (Roche Diagnostics $\mathrm{GmbH}$, D-68298 Mannheim, Germany); and troponin I tests were performed using Mini Vidas analyzer (Biomerieux). Analyses for BUN were performed via the kinetic method using urease and glutamate dehydrogenase; those for amylase were performed via the calorimetric enzymatic method, and those for troponin I were conducted via the enzyme-linked fluorescent immunoassay method.

\section{Histopathological evaluation}

Lung, brain, heart, and kidney tissues taken from the subjects were fixed in $10 \%$ neutral formalin. Sample tissues were submerged in paraffin after being put through degreed alcohol and xylene. 5- $\mu \mathrm{m}$-thick sections were taken and dyed with hematoxylin eosin and toluidine blue for general examination and for obtaining the mast cell count, respectively; and they were assessed using a $\mathrm{BH} 2$ Olympus light microscope. Histopathological evaluations were performed on each subject's lung, brain, heart, and kidney sample sections. Changes in the lung tissue were scored in terms of alveolar edema, hemorrhage, cell infiltration, and alveolar wall thickness. Scoring was assigned as normal structure (0), minor changes (1), moderate changes (2), and widespread changes (3) [15]. In the lung tissue of all subjects, the mast cell count was obtained at $40 \times$ scope magnification in 6 different areas. Histopathological scoring was performed by a researcher who was not informed about the subject groups.

\section{Statistical analysis}

The SPSS software package (SPSS version 17 for Windows) was used for statistical analyses. The values were presented as mean \pm standard deviation (SD), which is the normal distribution of the data, and as median \pm standard error (SE), which is not the normal distribution of data. For comparison among the groups, Kruskal-Wallis variance analysis, and for binary analysis, Mann-Whitney test with Bonferroni correction, were used. These differences were considered significant when probability was less than 0.05 .

\section{Results}

All subjects survived during the study process. Biochemical analysis revealed higher values of amylase in the control $(2747 \mp 1288,8)$ than in the other groups (group S:2182 $\mp 0$, group EPO:1931 420,4). The troponin I value was found to be $<0.001 \mathrm{ng} / \mathrm{mL}$ in all rats in the sham group, $<0.001 \mathrm{mg} / \mathrm{dL}$ in four rats and $0.5-22.97 \mathrm{ng} / \mathrm{dL}$ in five rats in the Control group, $<0.001 \mathrm{ng} / \mathrm{dL}$ in two rats and $0.2-0.9 \mathrm{ng} / \mathrm{dL}$ in all the remaining rats in the EPO group. The intergroup analyses showed no significant variations for amylase, BUN, and troponin I values but a statistically significant difference for the creatinine value ( $p=0.001)$ was. Binary comparisons showed that the 
difference in creatinine value was due to the Control (Median $\mp$ SE: $0,3 \mp 01$ ) and the EPO groups (Median $\mp$ SE: $0,2 \mp 0,005)(\mathrm{p}=0.001)$.

\section{Histopathological results}

No structural changes were observed in histopathological examinations of tissue samples taken from the kidney, brain, and heart but the lung. In the lung, parenchyma of control group subjects, capillary saturation and hemorrhage, inflammatory cell infiltration with accumulation of neutrophils, lymphocyte cell concentration around vessels, thickening of interalveolar walls, and fluid within some alveoli were identified (Figure 1a,b,c,d). Histological changes in the control and sham groups were also shown in Figure 2.

It was observed that in the subjects of the Control Group there were mast cells with spread granules in some areas; and in these areas edema was very significant (Figure 3a,b). In the EPO group, in addition to the mast cell count surrounding the vessels, hemorrhage and edema were observed to be reduced (Figure 3c). And the presence of scant amount of mast cells in sham group was shown in Figure 3d.

The scoring used in the histopathological assessment and the observed histopathological changes including alveolar congestion, hemorrhage, alveolar septal infiltration, and alveolar wall thickness are presented in Table 1 and Figures 1 and 3. There was no statistically significant difference in terms of alveolar congestion $(\mathrm{p}=0.368)$ in between-groups comparison. When hemorrhage, alveolar septal infiltration, and alveolar wall thickness scores were evaluated, a meaningful intergroup difference was found. In further analysis, a meaningful difference was found between the sham and the control groups, the sham and the EPO groups, also the control and EPO groups $(\mathrm{p}=0.001,0.002$, and 0.019 , respectively) in terms of hemorrhage. A similarly significant difference was observed in terms of both the alveolar septal infiltration and the alveolar wall thickness between the sham and the control groups in addition to the sham and the EPO groups ( $\mathrm{p}=0.001$ in both cases).

The median count of mast cells in lung tissue samples was determined as $8 \pm 0.5$ in the sham group (95\% CI, 7.1-9.7), $12 \pm 0.8$ in the control group (95\% CI, 10.5-14.8), and $9 \pm 0.3$ in the EPO group (95\% CI, 8.2-9.7). In the control group, pronounced edema and a large number of mast cells with spread granules surrounding the vessels were observed (Figure 3a,b). On the other hand, in the EPO group, in addition to the mast cell count surrounding the vessels, hemorrhage and edema were reduced (Figure 3c). In terms of mast cell count, a significantly difference was found $(\mathrm{p}=0.001)$ between the groups. Further analyses showed that this difference was due to the Control and the EPO groups $(\mathrm{p}=0.002)$. The mast cell count was observed to be significantly lower in the EPO group compared to the control group.

\section{Discussion}

Although AP is an organ disease, it can cause systemic diseases in other organs such as the lungs, heart, kidneys, and brain as well. In published case presentations, acute myocardial infarction has been identified in patients with AP. In these patients, despite the ST-T changes in ECG, enzyme variations, troponin I values, and post-angiography coronary arteries are found to be normal. It is attributed to the direct effect of proteolytic enzyme concentrations,

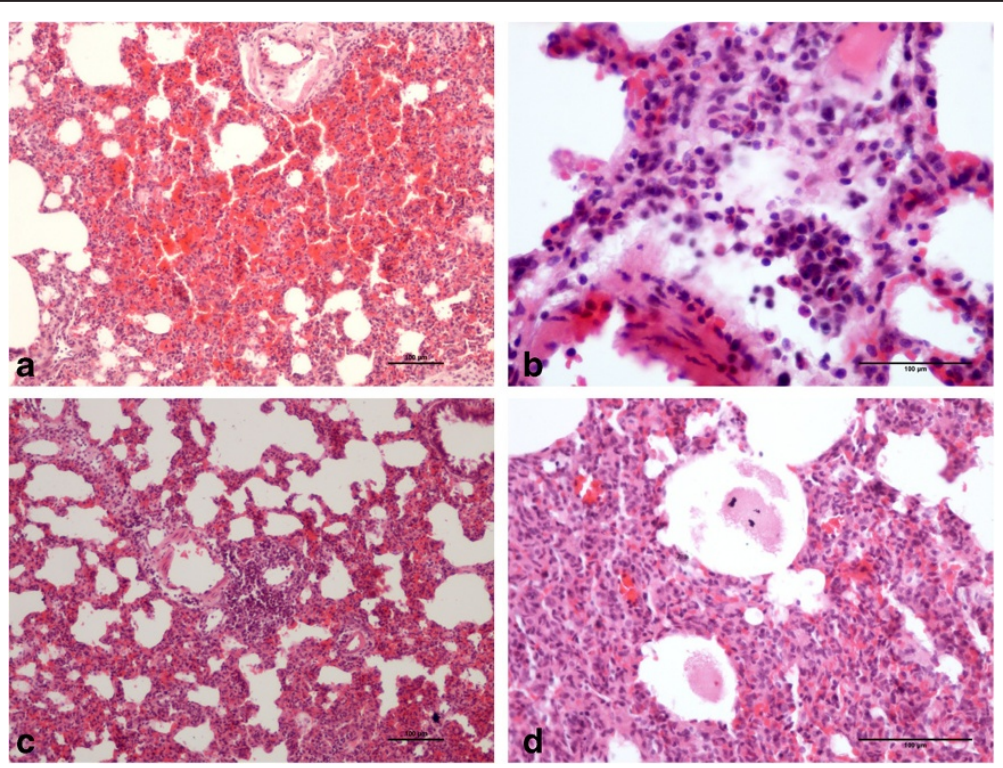

Figure 1 Histologic changes in the control group: (a) Extensive hemorrhage in lung parenchyma, (b) inflammatory cells neutrophil infiltration, (c) vascular proximity lymphocyte infiltration, (d) alveolar fluid (hematoxylin eosin-x40). 


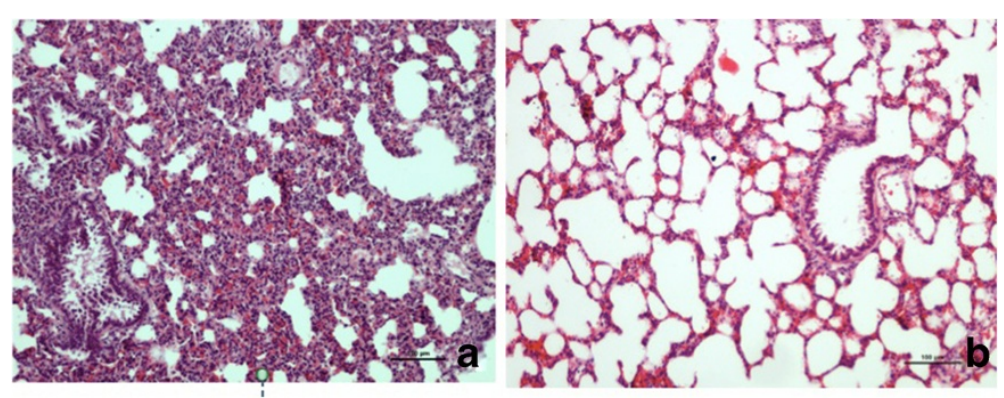

Figure 2 Histologic changes in the EPO and Sham groups: (a) reduced hemorrhage in the EPO group (hematoxylin eosin-x40), (b) histological appearance of the lung in the sham group(toluidine blue dye).

vasoactive and toxic substance release, vasovagal reflex, hypovolemia, electrolytic changes, and fat emboli on heart muscles [16-18]. In this study, no meaningful difference was observed in terms of troponin I values and histopathological assessments among rat groups with induced AP.

Acute renal failure is generally observed as a lethal complication of AP [19-21]. In this study, only the creatinine value of the kidney in the EPO group was found to be significantly lower than that of the control group. No changes were identified in terms of histopathology.

Among new treatment strategies, EPO therapy to retard the course of neurodegenerative diseases and slow down their damaging effects is considered promising [6,22,23]. Studies have already focused on the use of low molecular weight heparin, dexamethasone, and octreotide for encephalopathy developed in AP-induced rats [24,25]. However, as studies have not yet focused on EPO use for brain damage caused by induced AP, it is currently not possible to reach a conclusion on this issue. In this study, no histopathological changes were seen in the brain tissues of rats with induced AP. However, further studies may produce more detailed data on the inhibitive effect of EPO and secondary cerebral damage caused by AP.

SIRS and MOF are the most frequent causes of mortality in AP. Organ failures are considerably affected by pulmonary complications. Three major pathological mechanisms have been identified in ALI induced by pancreatitis: (1) pulmonary endothelial dysfunction, (2) leucocyte migration in interstitial area, and (3) distortion of wall permeability and gas exchange due to morphological pulmonary damage $[10,26]$.

Pancreatitis-related ALI (PALI) is seen as one of the causes of mortality in the initial days of the disease [10].

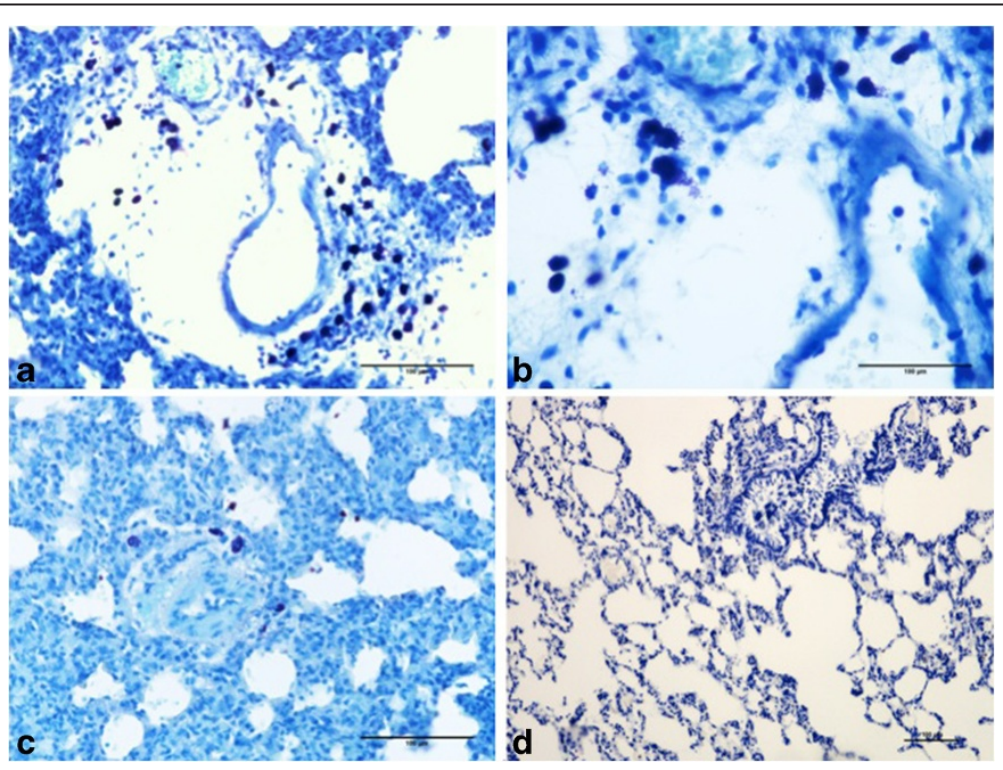

Figure 3 Distribution of mast cells in the groups: (a) Pronounced edema and a multitude of mast cells in vascular proximity of control group, (b) at larger magnification, the majority of mast cells are seen to be degranulated, (c) decreased mast cell count and edema in EPO group (toluidine blue dye), (d) rare mast cells in the sham group (toluidine blue dye). 
Table 1 Evaluation of the histopathologic changes in the lung

\begin{tabular}{lllll}
\hline Lung injury score & \multicolumn{2}{l}{ Groups [median (min-max)] } & p \\
\cline { 2 - 3 } & Sham & Control & EPO* & \\
\hline Alveolar congestion & 0 & $1(0-1)$ & 0 & 0,368 \\
Hemorrhage & 0 & $2(1-2)$ & $1(0-1)$ & 0,001 \\
Alveolar septal infiltration & 0 & $2(1-2)$ & $1(1-1)$ & 0,001 \\
Alveolar wall thickness & 0 & $2(1-2)$ & $1(1-1)$ & 0,001 \\
\hline
\end{tabular}

Histopathological score: "0" normal, "1"mild, "2"moderate.

*Group EPO: Erythropoietin therapy group.

Renner et al., through a study of 405 case autopsy examinations, identified that $60 \%$ of patients had pulmonary complications in the first week [27]. Johnson et al. identified pulmonary complications in $38-39 \%$ of patients [28]. Tascilar et al., by EPO (1000 U/kg, single dosage) therapy, identified a meaningful reduction in alveolar edema and polymorphonuclear cells (PMNL) in ALI induced by pancreatitis after $72 \mathrm{~h} \mathrm{[29].} \mathrm{Li} \mathrm{et} \mathrm{al.,} \mathrm{in} \mathrm{the} \mathrm{treatment} \mathrm{of} \mathrm{AP,}$ and Shang et al., in the treatment of lung injury caused by lipopolysaccharide, applied a single dose of $3000 \mathrm{U} / \mathrm{kg}$ EPO prior to the procedure. In both cases, positive histopathological results were obtained. Meaningful reduction in the lung tissue interstitial edema, hemorrhage, thickening of the alveolar wall, alveolar area, and inflammatory cell infiltration were identified in the EPO group [30,31]. This result was correlated with the anti-inflammatory effect of EPO. Although this study did not show a meaningful difference in terms of alveolar edema between the EPO group and the other groups, a meaningful difference was observed in neutrophils accumulated in alveolar septal cell infiltration in the EPO group compared to the control group. In contrast to our study, two cited studies have applied EPO therapy with a single $1000 \mathrm{U} / \mathrm{kg} /$ day dose. The EPO dosage is related to the cytoprotective inhibition effect. Dosages provide systemic cytoprotection at $100-1000 \mathrm{U} / \mathrm{kg}$, neuroprotection at $350-5000 \mathrm{U} / \mathrm{kg}$, and cardioprotection at 3000-5000 U/kg [14,32].

In this study, a dosage of $1000 \mathrm{U} / \mathrm{kg} /$ day (third dose) was used to reduce inflammatory cytokines and protect the cells from apoptosis. Alveolar edema developed secondary to pancreatitis is connected with the increase in microvascular permeability [27]. It may be considered that EPO protects endothelial cell integrity and reduces lung damage [29]. The data show that EPO administration can alleviate pulmonary injury parameters in pancreatitis.

Mast cells are important due to their location around blood capillaries and the lymphatic system and their ability upon activation to cause allergic and inflammatory diseases of the pulmonary system $[10,12]$. In ALI, the increase in pulmonary neutrophil infiltration may be related to the extreme activity of macrophages and resulting chemotactical neutrophil migration, which cause the release of various inflammatory mediators. In the ALI development process, pancreatitis activates mast cells and then leukocytes, which lead to endothelial wall dysfunction [10]. In a lung ischemia reperfusion experiment in which rats were administered mast cell stabilizer agent (cromolyn sodium) prior to the procedure, a reduction in inflammatory response was identified $[10,33]$. In the histopathological assessment of this study, the mast cell count of the EPO Group $(9 \pm 0.3)$ was observed to be significantly lower than that of the control group. The findings also support the therapeutic effect of EPO in ALI treatment, similar to available literature data.

\section{Conclusions}

EPO is effective in limiting lung damage secondary to AP. In this regard, it may be considered that it has positive effects in the reduction of mast cell count in the lungs, alveolar hemorrhage, septal neutrophil infiltration, and wall thickness. However, further studies are required to investigate the effects of EPO on the mast cells during ALI.

\section{Competing interests}

The authors declare that they have no competing interests.

\section{Authors' contributions}

All authors contributed equally to the writing and revision of the manuscript. All authors read and approved the final manuscript.

\section{Acknowledgement}

The outher thank to M.Murat Bozgeyik for his permission about supplying the tissues used in this study.

\section{Author details}

${ }^{1}$ Department of Emergency, Medicine of Faculty, Abant İzet Baysal University, Bolu, Golkoy, Turkey. ${ }^{2}$ Department of General Surgery, Medicine of Faculty, Abant İzzet Baysal University, Bolu, Turkey. ${ }^{3}$ Department of Thoracic Surgery, Medicine of Faculty, Abant Izzet Baysal University, Bolu, Turkey.

${ }^{4}$ Department of Histology and Embryology, Medicine of Faculty, Abant İzet Baysal University, Bolu, Turkey.

Received: 17 May 2013 Accepted: 17 April 2014

Published: 24 April 2014

\section{References}

1. Kingsnorth AN, Galloway SW, Formela LJ: Randomized, double-blind phase II trial of Lexipafant, a platelet-activating factor antagonist, in human acute pancreatitis. Br J Surg 1995, 82(10):1414-1420.

2. Bhatia M, Wong FL, Cao Y, Lau HY, Huang J, Puneet P, Chevali L: Pathophysiology of acute pancreatitis. Pancreatology 2005, 5(2-3):132-144.

3. Raraty MG, Connor S, Criddle DN, Sutton R, Neoptolemos JP: Acute pancreatitis and organ failure: pathophysiology, natural history, and management strategies. Curr Gastroenterol Rep 2004, 6(2):99-103.

4. Makhija R, Kingsnorth AN: Cytokine storm in acute pancreatitis. J Hepatobiliary Pancreat Surg 2002, 9(4):401-410.

5. Maiese K, Li F, Chong ZZ: New avenues of exploration for erythropoietin. JAMA 2005, 293(1):90-95.

6. Maiese K, Chong ZZ, Shang YC, Wang S: Erythropoietin: new directions for the nervous system. Int J Mol Sci 2012, 13(9):11102-11129.

7. Ghezzi P, Brines M: Erythropoietin as an antiapoptotic, tissue-protective cytokine. Cell Death Differ 2004, 11(1):37-44.

8. Bradding P: The role of the mast cell in asthma: a reassessment. Curr Opin Allergy Clin Immunol 2003, 3(1):45-50.

9. Wasserman SI: Mast cell biology. J Allergy Clin Immunol 1990, 86(4):590-593. 
10. Zhao X, Dib M, Wang X, Widegren B, Andersson R: Influence of mast cells on the expression of adhesion molecules on circulating and migrating leukocytes in acute pancreatitis-associated lung injury. Lung 2005, 183(4):253-264.

11. Payne V, Kam PC: Mast cell tryptase: a review of its physiology and clinical significance. Anaesthesia 2004, 59(7):695-703.

12. Huang P, Liu D, Gan X, Zhang R, Gao W, Xia Z, Hei Z: Mast cells activation contribute to small intestinal ischemia reperfusion induced acute lung injury in rats. Injury 2012, 43(8):1250-1256.

13. Su M, Chi EY, Bishop MJ, Henderson WR Jr: Lung mast cells increase in number and degranulate during pulmonary artery occlusion/reperfusion injury in dogs. Am Rev Respir Dis 1993, 147(2):448-456.

14. Kahramansoy N, Bozgeyik M, Erkol H, Bozcaarmutlu A, Kukner A, Buyukasik O: The effect of erythropoietin on intestinal damage developed secondary to experimental acute pancreatitis. Pancreat Disorders Ther 2012, 2(4):4.

15. Kim K, Li Y, Jin G, Chong W, Liu B, Lu J, Lee K, Demoya M, Velmahos GC, Alam HB: Effect of valproic acid on acute lung injury in a rodent model of intestinal ischemia reperfusion. Resuscitation 2012, 83(2):243-248.

16. Pezzilli $R$, Bellacosa $L$, Barakat B: Abdominal pain and ECG alteration: a simple diagnosis? Adv Med Sci 2010, 55(2):333-336.

17. Makaryus AN, Adedeji O, Ali SK: Acute pancreatitis presenting as acute inferior wall ST-segment elevations on electrocardiography. Am J Emerg Med 2008, 26(6):731-734.

18. Cafri C, Basok A, Katz A, Abuful A, Gilutz H, Battler A: Thrombolytic therapy in acute pancreatitis presenting as acute myocardial infarction. Int $\mathrm{J}$ Cardiol 1995, 49(3):279-281.

19. Yu J, Deng W, Wang W, Ding Y, Jin H, Chen C, Chen X, Xiong X, Xu S: Inhibition of poly(ADP-ribose) polymerase attenuates acute kidney injury in sodium taurocholate-induced acute pancreatitis in rats. Pancreas 2012, 41(8):1299-1305.

20. Nasir Kiran AA: Clinical course of acute pancreatitis in chronic kidney disease patients in a single kidney center (PGTi) in Karachi. Arab $J$ Nephrol Transplant 2012, 5(2):4.

21. Ljutic D, Piplovic-Vukovic T, Raos V, Andrews P: Acute renal failure as a complication of acute pancreatitis. Ren Fail 1996, 18(4):629-633.

22. Moore EM, Bellomo R, Nichol AD: Erythropoietin as a novel brain and kidney protective agent. Anaesth Intensive Care 2011, 39(3):356-372.

23. Brines $\mathrm{M}$ : What evidence supports use of erythropoietin as a novel neurotherapeutic? Oncology 2002, 16(9):79-89.

24. Qiu F, Lu XS, Huang YK: Protective effect of low-molecular-weight heparin on pancreatic encephalopathy in severe acute pancreatic rats. Inflamm Res 2012, 61(11):1203-1209.

25. Jingmin O, Xiping Z, Chun W, Ping Y, Qian Y: Study of dexamethasone, baicalin and octreotide on brain injury of rats with severe acute pancreatitis. Inflamm Res 2012, 61(3):265-275.

26. Milani RPP, Dolhnikoff M, Saldiva PHN, Martins NA: Respiratory mechanics and lung morphometry in severe pancreatitis-associated acute lung injury in rats. Crit Care Med 1995, 23:8.

27. Renner IG, Savage WT 3rd, Pantoja JL, Renner VJ: Death due to acute pancreatitis. A retrospective analysis of $\mathbf{4 0 5}$ autopsy cases. Dig Dis Sci 1985, 30(10):1005-1018.

28. Johnson CD, Kingsnorth AN, Imrie CW, McMahon MJ, Neoptolemos JP, McKay C, Toh SK, Skaife P, Leeder PC, Wilson P, Larvin M, Curtis LD: Double blind, randomised, placebo controlled study of a platelet activating factor antagonist, lexipafant, in the treatment and prevention of organ failure in predicted severe acute pancreatitis. Gut 2001, 48(1):62-69.

29. Tascilar O, Cakmak GK, Tekin IO, Emre AU, Ucan BH, Bahadir B, Acikgoz S, Irkorucu O, Karakaya K, Balbaloglu H, Kertis G, Ankarali H, Comert M: Protective effects of erythropoietin against acute lung injury in a rat model of acute necrotizing pancreatitis. World J Gastroenterol 2007, 13(46):6172-6182.

30. Li J, Luo Y, Li Z, Liu Y, Liu Z: Effects of erythropoietin pretreatment on pro-and anti-inflammatory balance in rats with severe acute pancreatitis. Nan Fang Yi Ke Da Xue Xue Bao 2012, 32(1):93-96.

31. Shang Y, Li X, Prasad PV, Xu S, Yao S, Liu D, Yuan S, Feng D: Erythropoietin attenuates lung injury in lipopolysaccharide treated rats. J Surg Res 2009, 155(1):104-110.
32. Bogoyevitch MA: An update on the cardiac effects of erythropoietin cardioprotection by erythropoietin and the lessons learnt from studies in neuroprotection. Cardiovasc Res 2004, 63(2):208-216.

33. Vural KM, Liao H, Oz MC, Pinsky DJ: Effects of mast cell membrane stabilizing agents in a rat lung ischemia-reperfusion model. Ann Thorac Surg 2000, 69(1):228-232.

doi:10.1186/1756-0500-7-267

Cite this article as: Korkmaz et al:: The effect of erythropoietin to pulmonary injury and mast cells secondary to acute pancreatitis. BMC Research Notes 2014 7:267.

\section{Submit your next manuscript to BioMed Central and take full advantage of:}

- Convenient online submission

- Thorough peer review

- No space constraints or color figure charges

- Immediate publication on acceptance

- Inclusion in PubMed, CAS, Scopus and Google Scholar

- Research which is freely available for redistribution

Submit your manuscript at www.biomedcentral.com/submit
C) Biomed Central 